\title{
The age of onset and sex distribution of insulin-dependent diabetes mellitus in Africans in South Africa
}

\author{
W.J. Kalk ${ }^{1}$, K.R.L. Huddle ${ }^{2}$ and F.J. Raal ${ }^{1}$ \\ Department of Medicine, University of the Witwatersrand and the Diabetes Clinics, ${ }^{1}$ Johannesburg and \\ ${ }^{2}$ Baragwanath Hospitals, Johannesburg, South Africa
}

\begin{abstract}
Summary: Type I (insulin-dependent) diabetes mellitus (IDDM) appears to be rare in indigenous African populations, but little detailed information has been published. We have therefore analysed the age of onset of diabetes in 176 African patients with IDDM (age of onset $<35$ years), and in 149 consecutive white patients of European extraction for comparison. In the Africans the peak age of onset occurred at 22-23 years (median 22 years) with an earlier peak from 14 to 17 years. In the Whites, the peak was found at 12-13 years (median 12 years). In only $7 \%$ of Africans did diabetes start under the age of 12 years. There was a slight female preponderance in the Africans, especially at the ages of greatest incident (20-25 years) - F:M 1.55:1. When patients with duration of diabetes less than 5 years only were analysed (the period during which early mortality among African patients was greatly reduced) the patterns of age distribution were similar to the total respective groups. A peak incidence in the winter months was noted.
\end{abstract}

\section{Introduction}

Compared with Western industrialized countries, Type I (insulin-dependent) diabetes (IDDM) appears to be an uncommon disorder in underdeveloped communities, including the Black African population of South Africa. ${ }^{1}$ There is, however, little detailed information on its prevalence in Africa. ${ }^{2}$ Apart from prevalence, there may also be other ethnic differences - Type I diabetes appears to be distinctly rare in African children, and several studies suggest that the age of onset of diabetes may be later in Africans compared to Caucasians..$^{3-7}$ In contrast, a recent North American study showed that Type I diabetes was only slightly less frequent in Black compared to White children, and that the ages of onset of diabetes were similar. ${ }^{6}$ In order to shed further light on possible ethnic differences or similarities we have analysed the age of onset and sex distribution in a relatively large group of African patients with Type I diabetes in Johannesburg, South Africa. A sample of Causcasian (White) patients was studied for comparison. In recent years the previously high early mortality from hyperglycaemia among our African patients ${ }^{7}$ has been drastically curtailed, ${ }^{8}$ so reducing this potential source of bias. ${ }^{2}$

Correspondence: Professor W.J. Kalk, F.R.C.P., Department of Medicine, Medical School, York Road, Parktown, 2193 Johannesburg, South Africa.

Accepted: 11 January 1993

\section{Subjects and methods}

The records of all living African patients with insulin-dependent diabetes, diagnosed under the age of 36 years and attending the diabetes clinics at Baragwanath Hospital in 1986 were studied. Baragwanath is the only hospital serving the urban population of Soweto - some 2 million Africans of all Southern African tribal origins. All had 'African' surnames and none of these subjects were known to have any White genetic admixture. Measurements of non-fasting serum C-peptide concentrations (Biodata Kit) were available in 28 African patients in 1991: 22 of these were from the original study (1987). A sample of 149 White diabetic patients (of Western and Southern European extraction), with age of onset of diabetes before 36 years, seen consecutively over a 4 month period at the Johannesburg Hospital, were studied for comparison. In 103 of these patients information was available on the month of diagnosis of diabetes and duration of symptoms before diagnosis.

In 1981 an intensive diabetes education programme was initiated at Baragwanath Hospital in an attempt to reduce the very high early mortality ${ }^{7}$ among diabetic Africans. A follow-up study after 5 years revealed a striking reduction in avoidable mortality. ${ }^{8}$ Thus data from African and White patients with duration of diabetes less than or equal to 5 years were studied separately. 
The chi-squared test was used in the statistical analyses.

\section{Results}

The distribution of age of onset of African and White diabetic subjects is depicted in Figure 1A and $B$, respectively. In the African patients the peak age of onset was a full decade later than in the white patients, at 22-23 years (median 22 years), with a possible earlier peak from 14 to 17 years of age, and a later peak at 30-31 years. In the White sample the peak age of onset was between 12 and 13 years followed by a steep decline. A small, late peak was evident from the age of 30 years.

The median duration of diabetes among the Africans was 4 years, compared to 7 years for the Whites. Diabetes had been diagnosed within the previous 5 years in 108 Africans $(61.4 \%)$ and in 69 White $(46.3 \%)$ patients. The patterns of age of onset for patients with duration of diabetes $<5$

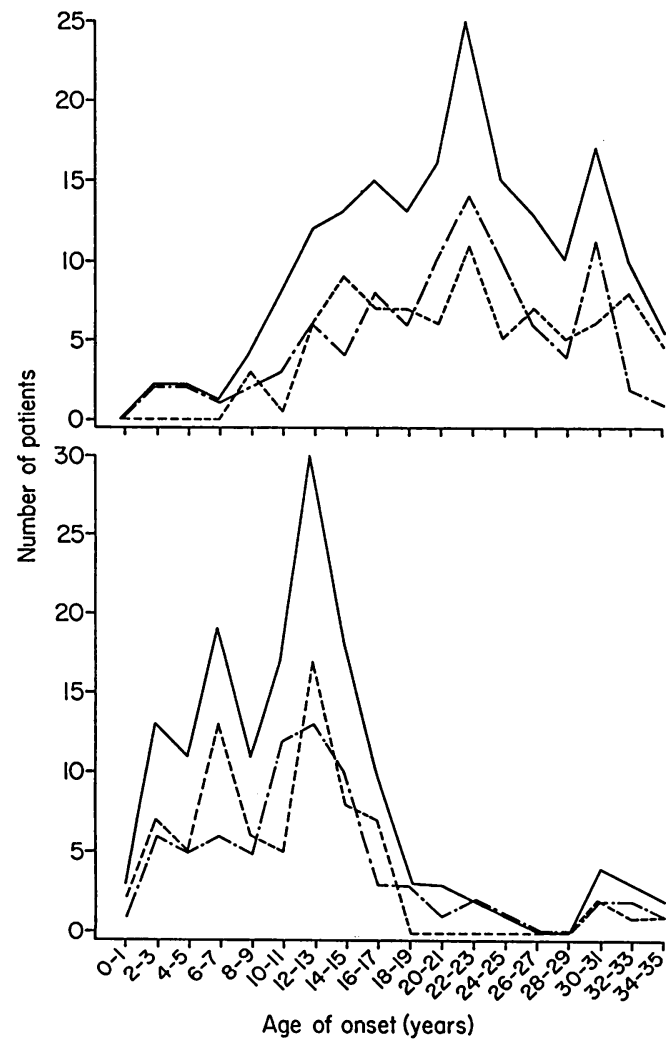

Figure 1 The distribution of ages of onset of patients with Type I (insulin-dependent) diabetes. (A) African patients; (B) White patients. $=$ total; $---=$ males; $---=$ females. years in each ethnic group were similar to their respective total groups, except that in both there were fewer patients with very young age of onset (Figure 2).

The overall male:female ratio in the Africans was $1: 1.3$; in the 6 years of the peak age of incidence (20-25 years) the ratio was 1:1.55. Diabetes was diagnosed in childhood ( $<12$ years of age) in only 12 subjects $(7 \%)$. The youngest male patients were 8-9 years old and the youngest females were 2 years old at the onset of diabetes.

Data were available on unstimulated, nonfasting serum C-peptide in 28 of the African patients (12 female), aged $29.2 \pm 5.7$ years. The median age of onset of diabetes in this subgroup was also 22 years (range 9-30 years), and the duration of diabetes $7.0 \pm 3.3$ years. In $21(75 \%)$ C-peptide was undetectable $(<0.03 \mathrm{nmol} / \mathrm{l})$ and

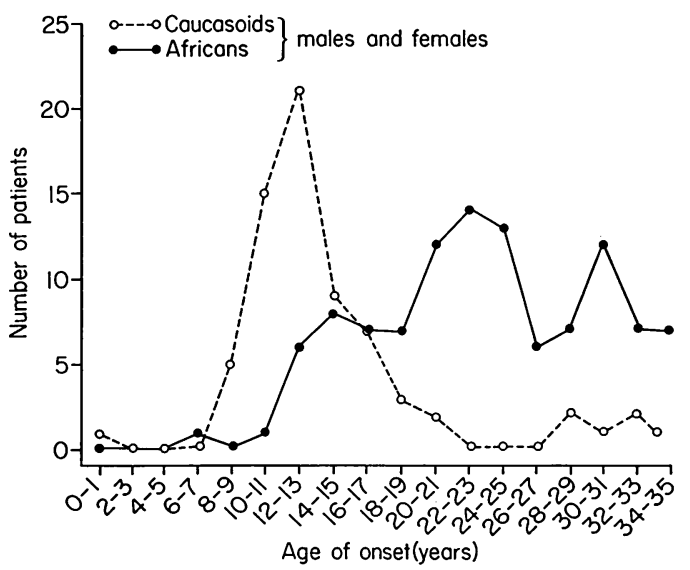

Figure 2 The ages of onset of combined male and female African and Caucasian patients with Type I diabetes of duration $<5$ years.

Table I Patients in whom non-fasting serum C-peptide was measured, divided according to C-peptide status

\begin{tabular}{lcc}
\hline & \multicolumn{2}{c}{ C-peptide } \\
& Undetectable & Detectable \\
\hline Sex (M:F) & $14: 7$ & $2: 5$ \\
$\begin{array}{l}\text { Age (years) } \\
\text { Body mass index } \\
\left(\mathrm{kg} / \mathrm{m}^{2}\right)\end{array}$ & $28.9 \pm 6.4$ & $30.0 \pm 2.9$ \\
$\begin{array}{c}\text { Age of onset of DM } \\
\text { (years) }\end{array}$ & $21.6 \pm 5.9$ & $21.5 \pm 5.3$ \\
$\begin{array}{c}\text { Duration of DM } \\
\text { (years) }\end{array}$ & $7.3 \pm 4$ & $6.5 \pm 3.1$ \\
\hline
\end{tabular}

$\mathrm{DM}=$ diabetes mellitus. 
ranged from 0.03 to $0.18 \mathrm{nmol} / 1$ in the remaining seven subjects, four of whom were overweight (Table I).

The peak months of diagnosis and symptomatic onset in the White patients were June and July, which coincide with the lowest average day and night temperatures in Johannesburg (Figure 3).

\section{Discussion}

The inhabitants of Soweto are made up of negroid peoples from all indigenous language groups of South Africa, who have been shown to exhibit very little genetic admixture with Caucasian peoples. ${ }^{9}$

Every effort was made to collect information about all living African patients with Type I diabetes who attended Baragwanath Hospital. Although it is most likely that most Africans with IDDM in this area attended this hospital, this was a hospital-based study with potential selection bias. It was not possible to trace the records of deceased patients, so bias caused by early death also remains. Furthermore, more than half the living patients had had diabetes for 5 years or less. Thus either
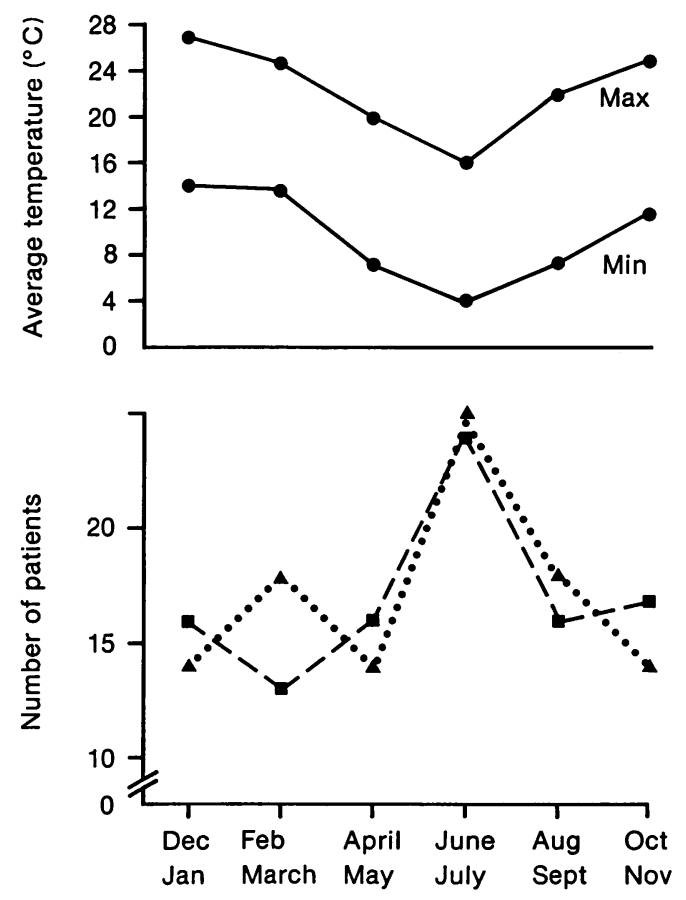

Figure 3 The months of diagnosis (dotted line) and onset of symptoms (dashed line) among 103 white insulindependent subjects, and average maximum and minimum temperatures (provided by the Bureau of Statistics, Pretoria, RSA). there had been a recent increase in diabetes in this population, or, more likely, the short duration of diabetes reflected the cumulative effect of a previous high early mortality rate., ${ }^{2,7}$

More than $80 \%$ of the subjects in whom nonfasting serum C-peptide concentrations were measured had levels $\leqslant 0.03 \mathrm{nmol} / 1-$ in $75 \%$ it was undetectable. These data confirm a recent report ${ }^{10}$ that the majority of young diabetic Africans are truly insulin deficient.

Our data suggest that the peak age of onset of IDDM in this African population occurred in subjects aged 22-23 years, a full decade later than in those of European extraction, in whom the pattern of age of onset was very similar to those reported from Europe. ${ }^{11-13}$ In the Africans, an earlier broad peak, from 14 to 17 years, may also be present. A possible later, smaller peak was apparent in both ethnic groups at 30-35 years of age. Analysis of patients with duration of diabetes of 5 years or less, the period during which avoidable mortality from diabetes was declining in the African patients ${ }^{8}$ so reducing the bias of premature mortality, revealed age distributions which were almost identical to those of the respective total groups. Thus there does appear to be a real racial difference in the ages of presentation of Type I diabetes, with strikingly few preadolescent Africar children. A similar pattern, with the peak age of onset between 21 and 30 years (mean age 23. years) has been described in smaller numbers of Natal Africans with IDDM, ${ }^{5}$ and in Ethiopians with insulin-dependent diabetes. ${ }^{14}$ In these studies only $11.6 \%$, and $10.8 \%$ of cases, respectively, were diagnosed under the age of 10 years. In Tanzania ${ }^{15}$ the peak seemed a little earlier, at 15-19 years, perhaps reflecting a population at risk for diabetes comparable to that of the minor peak in our patients, at roughly 14-17 years; diabetes developed in childhood in fewer than $5 \%$ of cases. Our figure of $7 \%$ of patients developing IDDM in childhood is in agreement with these reports from elsewhere in Africa.

Many authors have commented on the rarity of diabetes in African children - missed diagnosis (as 'gastroenteritis') and high mortality from ketoacidosis may have contributed to small numbers of surviving children. At Baragwanath Hospital thousands of very young children with gastroenteritis are treated each year: hyperglycaemia and ketonuria are common at presentation in these infants (and diabetes is frequently suspected), but both rapidly settle without insulin therapy. ${ }^{16}$ It is unlikely therefore, that in this age group at least, the diagnosis of diabetes has been missed in recent years.

The apparent older onset of diabetes in our African patients contrast with the almost uniformly younger peak age of onset seen in other 
racial groups. ${ }^{1,17-19}$ In Black Americans Type I diabetes is less frequent than in Whites but the age distributions at diagnosis are similar, ${ }^{6}$ possibly because of the very considerable White genetic admixture. ${ }^{20,21}$ The reasons for the observed age differences in Africans are not clear. We do not have data on immunological markers for IDDM, but islet cell antibodies are prevalent in young Black diabetic South Africans, ${ }^{22}$ suggesting that the pathogenesis of diabetes in this population is the same as in other races. On the other hand, in Black South Africans the patterns of HLA antigen inheritance and associations with diabetes differ from those of other races, although conflicting results have been produced. In one series, ${ }^{23}$ but not in another, ${ }^{24} \mathrm{a}$ significantly increased frequency of HLA-DR4 but not DR3 was found in insulindependent African diabetic patients. In Europe, HLA-DR4 is, however, associated with younger rather than older age of onset of diabetes. ${ }^{25}$ Another possibility is that Africans may be exposed at a later age to environmental factors which are thought to initiate the diabetic autoimmune processes in genetically predisposed individuals. ${ }^{26}$ However, many viral illnesses, such as measles, poliomyelitis and hepatitis generally occur in early childhood in Africans. Thus later exposure to viral initiators of diabetes ${ }^{27}$ is an unlikely explanation for the later onset in Africans. Finally, regional differences in the incidence and seasonal onset of Type I diabetes have been described elsewhere, ${ }^{28-31}$ implicating local differences in exposure to environmental initiating or precipitating factors. In recent years there has been a major shift of African populations from the countryside to industrial urban centres: later exposure to 'urban'

\section{References}

1. Zimmet, P. Epidemiology of diabetes. In: Ellenber, M. \& Rifkin, H. (eds) Diabetes Mellitus, Theory and Practice. Medical Examination Publishing Co, Inc, New York, 1983, pp. 451-468.

2. McLarty, D. Diabetes in Africa. In; Krall, L.P. (ed.) World Book of Diabetes in Practice, vol. 2. Elsevier, Amsterdam, 1986, pp. 218-228.

3. Kwaku Adadevoh, B. Endocrine patterns in the African. Trop Geogr Med 1970, 22: 125-141.

4. Asmal, A.C., Jialal, I., Leary, W.P. et al. Insulin-dependent diabetes mellitus with early onset in Blacks and Indians. $S$ Afr Med J 1981, 60: 91-93.

5. Omar, M.A.K. \& Asmal, A.C. Patterns of diabetes mellitus in young Africans and Indians in Natal. Trop Geogr Med 1984, 36: 113-138.

6. Le Porte, R.E., Tajima, N., Durman, J.S. et al. Differences between blacks and whites in the epidemiology of insulin dependent diabetes mellitus in Allegheny county, Pennsylvania. Am J Epidemiol 1986, 123: 592-603.

7. Buch, E., Irwig, L.M., Huddle, K.R.L., Krige, L.P., Krut, L.H. \& Kuyl, J.M. Pointers to preventing hyperglycaemic emergencies in Soweto. S Afr Med J 1983, 64: 705-709. diabetogenic factors could possibly contribute to the older age of onset in this group.

Very little information concerning the sex ratios of Africans with insulin-dependent diabetes is available. In the present series females outnumbered the males, especially around the peak age of onset and in children less than 11 years of age. Omar et al. ${ }^{5}$ also found a female preponderance in their patients aged less than 35 years at diagnosis. In Ethiopians with Type I diabetes aged less than 20 years at onset, the male:female ratio was $0.8: 1$, but the ratio was reversed if all patients younger than 30 years were included. ${ }^{14}$ In young Japanese ${ }^{18}$ and American blacks $^{6}$ with diabetes, females also outnumbered males.

More cases among the White patients were diagnosed during the coldest winter months, in keeping with the known seasonal variation in onset of insulin-dependent diabetes, ${ }^{32}$ including black South Africans. ${ }^{5}$

In summary, the peak age of onset of insulindependent diabetes in urban Africans appears to be a decade later than in most other populations studied. Females seem to outnumber males, as in some other low prevalence populations. The great majority do not have detectable circulating Cpeptide and are truly insulin deficient.

\section{Acknowledgement}

The secretarial assistance of Mrs B. Head is gratefully acknowledged. We thank Sisters J. Constable, D. Green, N. le Blanc, C. Osler and D. Taylor of the Johannesburg Hospital Diabetes Clinic for their invaluable assistance.

8. Huddle, K.R.L. \& Gill, G.V. Reducing acute hyperglycaemia mortality in African diabetic patients. Diabet Med 1988, 6: 64-66.

9. Nurse, G.T., Weiner, J.F. \& Jenkins, T. The Peoples of Southern Africa and Their Affinities. Oxford University Press Oxford, 1985, pp. 162-185.

10. Gill, G.V. \& Huddle, K.R. Patterns of insulin dependence in an African Diabetic Clinic. Quart J Med 1991, 294: 829-835.

11. Christau, B., Kromann, H., Christy, M., Anderson, O.O. \& Nerup, J. Incidence of insulin-dependent diabetes mellitus (0-29 years at onset) in Denmark. Acta Med Scand 1979, 624 (Suppl): 54-60.

12. Gamble, D.R. The epidemiology of insulin dependent diabetes, with particualr reference to the relationship of virus infection to its etiology. Epidemiologic Rev 1980, 2: 49-70.

13. Patterson, C.C., Thorogood, M., Smith, P.G., Heasman, M.A., Clark, J.A. \& Mann, J.I. Epidemiology of Type I (insulin-dependent) diabetes in Scotland 1968-1976: evidence for an increasing incidence. Diabetologia 1983, 24: 238-243.

14. Lester, F.T. The clinical pattern of diabetes in Ethiopians. Diabetes Care 1984, 7: 6-11. 
15. Swai, A.B.M., Lutale, J. \& McLarty, D.G. Diabetes in tropical Africa: a prospective study 1981-1987. $\mathrm{Br} \mathrm{Med} \mathrm{J}$ 1990, 300: 1103-1110.

16. Rabinowitz, L., Joffe, B.I., Abkiewitz, C., Shires, R., Greef, M.C. \& Seftel, H.C. Hyperglycaemia in infantile gastroenteritis. Arch Dis Child 1984, 59: 771-775.

17. Fleegler, F.M., Rogers, K.D., Drash, A., Rosenbloom, A.L., Travis, L.B. \& Court, J.M. Age, sex and season of onset of juvenile diabetes in different geographic areas. Paediatrics 1979, 63: 374-379.

18. Tajima, N., La Porte, R.E., Hibi, I., Kitagawa, T., Fujita, H. \& Drash, A.L. A comparison of the epidemiology of youth onset insulin dependent diabetes mellitus between Japan and the United States (Allegheny County, Pennsylvania). Diabetes Care 1985, 8 (Suppl 1): 17-23.

19. Laron, Z., Karp, M. \& Modan, M. The incidence of insulin dependent diabetes mellitus in Israeli children and adolescents $0-20$ years of age: a retrospective study 1975-1980. Diabetes Care 1985, 8 (Suppl 1): 24-28.

20. Reed, T.E. Caucasian genes in American negroes. Science 1969, 165: 762-768.

21. MacDonald, M.J. Hypothesis: the frequency of juvenile diabetes in American Blacks and Caucasians are consistent with a dominant inheritance of juvenile diabetes. Diabetes 1980, 29: $110-114$.

22. Omar, M.A.K., Bottazzo, G.F. \& Asmal, A.C. Islet cell antibodies and other autoantibodies in South African Blacks and Indians with insulin-dependent diabetes mellitus (IDDM). Hormone Metab Res 1986, 18: 126-128.

23. Omar, M.A.K., Hammond, M.C. \& Asmal, A.C. HLA$A, B, C$ and DR antigens in young South African black Type I (insulin-dependent) diabetes mellitus. Diabetologia 1984, 26: 20-23.
24. Orren, A., Taljaard, D. \& du Toit, E. HLA-A,B,C and DR antigen associations in insulin dependent diabetes mellitus (IDDM) in South African Negro (Black) and Cape Coloured people. Tissue Antigens 1985, 26: 332-339.

25. Lugvigsson, J., Samuelsson, U., Beauforts, C. et al. HLADR3 is associated with a more slowly progressive form of $c$ Type I (insulin dependent) diabetes. Diabetologia 1986, 29: 207-210.

26. Leslie, R.D.G. Causes of insulin dependent diabetes. $\mathrm{Br} \mathrm{Med}$ $J$ 1983, 287: 5-6.

27. Krolewski, A.S., Warram, J.H., Rand, L.I. \& Kahn, C.R. Epidemiologic approach to the etiology of Type I diabetes mellitus and its complications. $N$ Engl $J$ Med 1987, 317 1390-1398.

28. Sterky, G., Holgren, G., Crustavson, K.H. et al. The है incidence of diabetes mellitus in Swedish children 19701975. Acta Paediatr Scand 1978, 67: 139-143.

29. Christau, B., Kromann, H., Andersen, O.O. et al. Incidence, seasonal and geographical patterns of juvenile-onset insulindependent diabetes mellitus in Denmark. Diabetologia 1977, 13: $281-284$.

30. Joner, G. \& Sovik, O. Incidence, age of onset and seasonal variation in diabetes mellitus in Norwegian children 1973-1977. Acta Paediatr Scand 1981, 70: 329-335.

31. Allen, C., Palta, M. \& D'Alessco, J.D. Incidence and differences in urban-rural seasonal variation of Type I (insulin-dependent) diabetes in Wisconsin. Diabetologia 1986, 29: 629-633.

32. Durrity, P., Ruiz, F. \& Carcia de los Rios, M. Age at diagnosis and seasonal variation in the onset of insulindependent diabetes in Chile (Southern Hemisphere). Diabetologia 1979, 63: 374-379. 